\title{
COMPARATIVE STUDY AND ANALYSIS OF PUNE BRTS AND HUBBALLI DHARWAD BRTS IN INDIA (2018-2019)
}

\author{
Prof: Vithal Hanumantrao Jadhav, Er. Janakaraj M. Halamani, Er. Sangamesh Katagi, Er.Kundan Pailwanawale, \\ Er Shivansa Laxmansa \\ Prof and Final Semester Students, School of Civil Engineering. K.L.E Technological University Vidyanagar Hubballi \\ Karnataka INDIA
}

\begin{abstract}
The increase in population is the main cause for rapid increase in the traffic intensity on roads. It has become almost indispensible in human life. Problem of traffic control within city limits and between twin cities needs innovative solutions in all metropolitan cities all over the world. The efforts are being made every day to find out innovative solutions. In order to cop up with the increased traffic, it is a usual practice of increasing capacity of the roads. But this has limited scope as it involves huge land acquisition, dismantling of the existing structures and heavy compensation especially within city limits along the corridors. So, some mass transport systems are introduced viz., increasing local train service, providing monorail, light rail, metro services and adopting bus rapid transit system. Among these Bus Rapid Transit System (BRTS) is the most convenient system which can be adopted at lower construction and maintenance cost for medium traffic. This covers more commuters with more number of stops with ease of boarding and alighting. Bus rapid transit system (BRTS), also called as a bus way or transit-way which is a bus based public transport system designed to improve capacity and reliability relative to a conventional bus system with additional safety, comfort of public and to overcome traffic congestion. BRTS aims to combine the capacity and speed of a metro with flexibility at lower cost with ease of implementation of the bus transportation system. BRTS also provides higher level of service to the public. In this regard the continual improvement in BRTS is required based on the shortfalls in existing and functioning bus rapid transit systems at different parts of India. So a case has been taken up as a comparative study and analysis of Pune BRTS of Maharashtra state and Hubballi-Dharwad BRTS of Karnataka state of India, to enlighten the facts so as to enable to improve these systems and also to the planner to adopt in the future BTRS planning for different parts of India and abroad.
\end{abstract}

Keywords - BRTS, Traffic control, Traffic congestion, Mass transport,

\section{INTRODUCTION}

To adopt bus rapid transit system, it is required to study the existing transport problems of city. The study of existing system is to address the existing transport problems and to implement alternative advanced Public Mass Transportation System to improve the safety and level of service for private traffic, both local and through traffic by increasing the mobility and also to increase the capacity. Mass transport system is to meet the future travel demand and to reduce the traffic congestion on existing roads. BRTS is also to save time and cost and reduce the environmental impacts.

\section{PUNE BRTS:[1]}

Pune is the eighth largest city in India and the second largest in the state of Maharashtra, after Mumbai. Its Population is 5 million as per 2009 census. The city has an Area of 450.69 $\mathrm{km}^{2}$. At the end of March 2006, total registered vehicles were 1350210. Out of which 1017753 were two wheelers. The rate of increase in vehicles is 60000 per year. Pune Once the "Cycle City" is now a "Motor Cycle City". In December 2006, Pune became the first city in India to operate a pilot project of Bus Rapid Transit System (BRTS). It is planned to construct 5 corridors. First corridor has been constructed on a $16.20 \mathrm{~km}$ stretch between Katraj to Hadapsar via Swargate. At the time of study it is noted that 4 corridors are functioning and 1 corridor is under construction. Further details of Pune BRTS are as below:

Number of buses: 1023 - 12m length buses. 200 - mini buses.

Depots $\quad-13$,

Workshops -03 .

Foot Over Bridges - 02

Bus stops $\quad-91$

Bus terminals $\quad-03$

Fare collection - On board. 


\section{International Journal of Engineering Applied Sciences and Technology, 2020 Vol. 4, Issue 11, ISSN No. 2455-2143, Pages 212-217 \\ Published Online March 2020 in IJEAST (http://www.ijeast.com)}

\section{IMPORTANT COMPONENTS OF BRTS:}

Buses: Over 1000 special Rainbow BRT buses with doors on both sides and more standing space, that ply smoothly and rapidly in reserved lanes.

Bus stations: Stations are covered to provide protection from rain, dust and sun heat. Ramp at the entrance and signage boards with information about the BRT corridors are provided inside the bus station.

Doors: Automatic doors are provided for BRT stations and buses. Both station and bus doors open only when the bus is properly docked at the station through sensors.

Boarding: Level boarding is provided.The height of the bus floor and the BRT station platform are at the same level. Passengers do not have steps to board and alight the bus which is a feature similar to metro rail.

Crossings: The crossings from the footpath to the BRT stations have signals in many locations $\&$ have speed tables so that vehicles have to slow down to allow passengers to cross safely.

Bus Arrival and Station Information:

- Information on bus arrivals and departure is displayed on screens inside bus stations.

- Display screens and audio announcements in buses give information about the next stop in advance.

- Route numbers appear on LED displays on the front, back and the left side of buses.

Intelligent Transit Management System or Intelligent Transport System ITS: Buses are provided with Global Positioning System (GPS). All the buses and bus stations are linked with the BRTS Control Room at Swargate, which tracks bus movement and gives feedback to drivers to improve service.

Security and Traffic Management:

Security personnel are appointed at each BRT bus station.

Traffic Wardens are present at signals and crossings to help in the management of other traffic i.e., Mixed Traffic and to prevent entry into dedicated BRTS bus lanes.

\section{IV. $\quad$ SHORT FALLS OF PUNE BRTS:[1]}

i) Number of Buses: The Pune Mahanagar Parivahan Mahamandal Limited (PMPML). has about 1000 buses which are quite inadequate to serve throughout the city.

ii) Condition of Buses: The buses need to be maintained to the expected service level. They resemble some primitive mechanical contraptions.

iii) Uncomfortable transportation: Buses are overcrowded particularly during peak hours due to insufficient buses and travelling is miserable.

iv) Capacity of roads: The capacity of lanes is not sufficient for safe overtaking of long route buses / nonstop buses. v) Pavement: Flexible pavement is provided throughout the corridor, which is being deteriorated due to fatigue and rutting failure, especially at wheel locations at bus stops.

vi) Ticket collection: Rainbow BRTS having onboard ticket collection system leads to delay in running BRTS buses especially when buses are overcrowded.

vii) Uncontrolled mixed traffic on BRTS corridors: Many private vehicles such as cars, rickshaw, and motor-vehicles are plying on BRTS lanes which lead to delay in travelling time.

viii) Arboriculture system: The rainbow BRTS is not having arboriculture system along its medians which leads to soil erosion.

ix) Safety inside buses: The following safety measures are not witnessed.

- Fire extinguisher.

- Seat belts.

- Emergency exits.

- Stop buttons.

- Locking system for wheel chairs of physically disabled persons.

\section{MERITS OF PUNE BRTS:}

- Covered bus stations provide protection to commuters and the station from rain, dust and sun heat.

- Stations have ramp at the entrance for the easy movement of physically disabled persons also.

- Digital signal boards with information about the BRTS corridors are provided inside the bus stations and buses which enable the commuters to get the information about buses and respective routes for their travel.

- The Rainbow BRTS is provided with "PMPE connect" -app which facilitates passengers to access bus schedule.

\section{HUBLI-DHARWAD BRTS:[2]}

After the success of Ahmedabad BRTS (JANMARG) of Gujarat in India, Hubli-Dharwad is to have the first BRTS in Karnataka (HDBRTS). Which is "A Crown to Twin Cities"?

\section{BASIC INFORMATION:}

Twin cities are separated by about $20 \mathrm{~km}$.

Single Municipal area: $202 \mathrm{~km}^{2}$

Population: 0.94 million as per census (2011) Density of population: 4678 persons per $\mathrm{km}^{2}$.

Hubballli is Commercial centre and business hub of the region. Dharwad is an administrative seat of District and Educational hub of the region. Traffic growth is 10 to $14 \%$ per year during study. Two wheelers form about $67 \%$ of total traffic. Population growth is predicted 14.50 lakh by 2031 . 


\section{STAKE HOLDRES INVOLVED IN URBAN TRANSPORT IN HUBLI-DHARWAD}

i) R.T.O (Regional Transport Office)

ii) N.W.K.R.T.C (North West Karnataka Road Transport Corporation)

iii) Karnataka Public Works Department (KPWD)

iv) Karnataka Pollution Control Board

v) Police department

vi) H.D.M.C (Hubballi Dharwad Muncipal Corporation).

vii) H.D.U.D.A (Hubballi Dharwad Urban Development Authorities)

viii) K.R.D.C.L (Karnataka Road Development Corporation Ltd

\section{METHODOLOGY FOLLOWED:}

In order to undertake the project, several BRTS meetings were held with key stakeholders and public in Bengaluru (Capital city of Karnataka) and Hubli-Dharwad twin cities with a view to understand the governance structure in the state and the city and assessed the strengths and weaknesses of relevant departments and organizations from the point of view of their participation in the proposed service in Hubli-Dharwad. Based on the information collected from these meetings and a review of the relevant documents, an assessment was made regarding the roles and responsibilities of different institutions as well as their broad organization structures. A review of literature on the international best practice in the management of BRT systems was carried out, along with an interview of some experts. Thereafter, a list of possible options was prepared. In preparing this list, the effort was made to ensure that a well coordinated and comprehensive approach for managing the BRTS would be possible. The advantages and disadvantages of each option was analysed and has been presented in the report.

\section{PROJECT PARTNERS:}

Implemented by Hubli - Dharwad BRTS Company Ltd.Govt. of Karnataka undertaking.

Acquisition of Land and Development of BRTS corridor is taken up by KRDCL.

\section{KEY PARTNERS:}

- NWKRTC (Bus Operator).

- HDMC (Hubballi Dharwad Municipal Corporation).

- HDUDA (Hubballi Dharwad Urban Development Authority).

\section{DETAILS OF INFRASTRUCTURE:}

- BRTS depot beside new bus stand Hubballi.

- Bus terminal in Hosur.
- There are total 32 bus-stops provided from Hubballi railway station to Jubilee circle Dharwad.

- BRTS depot beside new bus stand Dharwad.

- BRTS bus terminal beside old bus stand Dharwad.

- Navanagar, Unkal cross, \& Unkal are provided with total 3 Grade Separators.

- There are total 6 FOB (foot over bridge) at Hosur stop, Prerana college, Unkal, Navnagar, Rayapur Iskcon temple, Sattur SDM medical college.

\section{HDBRTS BUS DETAILS:}

It is planned for total 130 buses for 1st stage. Out of which 100 Volvo buses of $12.00 \mathrm{~m}$ length. And 30 Volvo Articulated buses. All the buses are provided with air-conditioned.

Compared to other normal buses, BRTS bus produces only 70 $\mathrm{db}$ of sound.

Level Boarding: Floor Level of bus and stations is $900 \mathrm{~mm}$. Lane width of corridor:

Table 1. Lane width of corridor (each lane-7.50m)

\begin{tabular}{|c|c|c|c|c|}
\hline R.O.W in $\mathrm{m}$ & $\begin{array}{c}\text { Distance in } \\
\mathrm{km}\end{array}$ & From & To & $\begin{array}{c}\text { No. Of } \\
\text { lanes }\end{array}$ \\
\hline 35 & 4.02 & $\begin{array}{c}\text { Hosur cross } \\
\text { Hubballi }\end{array}$ & $\begin{array}{c}\text { Hotel } \\
\text { Naveen } \\
\text { Hubballi }\end{array}$ & 7 \\
\hline 44 & 11.87 & $\begin{array}{c}\text { Hotel Naveen } \\
\text { Hubballi }\end{array}$ & $\begin{array}{c}\text { Gandhinagar } \\
\text { cross, } \\
\text { Dharwad. }\end{array}$ & 8 \\
\hline 35 & 2.09 & $\begin{array}{c}\text { Gandhinagar } \\
\text { cross, } \\
\text { Dharwad. }\end{array}$ & $\begin{array}{c}\text { Jubilee } \\
\text { circle, } \\
\text { Dharwad. }\end{array}$ & 7 \\
\hline
\end{tabular}

XIV. IMPORTANT COMPONENTS OF BRTS:

Road way: Exclusive dedicated lanes generally along existing carriageway, that allow BRTS vehicles to be free from conflicting automobile traffic, parked or stopped vehicles, and other obstructions for maximizing smoothening BRTS operating speeds.

Vehicles: Modern, high capacity pneumatic -tired vehicles that accommodate a high volume of passengers and allow fast boarding and alighting from another crucial component of the BRTS (Uro-4).

Buses operations: Includes running of buses, driver management, routing and operational techniques and form other important components of a BRT's.

Fare collection: An advanced system of automated fare collection is a critical component of a BRT system, generally designed to make fare collection fast and easy to pay often 


\section{International Journal of Engineering Applied Sciences and Technology, 2020 \\ Vol. 4, Issue 11, ISSN No. 2455-2143, Pages 212-217 \\ Published Online March 2020 in IJEAST (http://www.ijeast.com)}

before boarding the vehicle. Collection system is made as prepaid by the use of integrated smart cards and QR tickets.

Picture 1 shows the ticket sample.

Intelligent Transport System (ITS) and control System/ Passenger information systems: ITS is adopted to improve customer convenience, speed, reliability, and safety. Examples include systems that provide traffic signal preference for buses at intersections and cross streets, as well as Global Positioning Systems (GPS) to provide passenger information such as realtime bus arrival information.

$$
\begin{aligned}
& \text { ITS includes: } \\
& \text { Automated Fare Collection System. } \\
& \text { Automated Vehicle Location System. } \\
& \text { Pehicle Scheduling and Dispatch System. } \\
& \text { Passenger Information System. } \\
& \text { Bustem. } \\
& \text { Fouse System. } \\
& \text { Incident Management System. } \\
& \text { Automated Boarding Gates and Electronic } \\
& \text { Docking System. } \\
& \text { Video Surveillance System. } \\
& \text { Business Intelligence Platform. }
\end{aligned}
$$

At grade junctions are provided with synchronised signals. The advanced sensor based traffic control system is developed by K.L.E. Technological University Hubballi and made known to the concerned HDBRTS authorities. The adoption of the same is under process. This helps in minimising the accidents especially at junctions.

Bus stops or shelters: The bus stops are located with a distance of about $500 \mathrm{~m}$ all along the corridor.

Bus terminals: Transit terminal stations require larger areas as they act as interchange points for more than one route. Terminals need to be added to take a turn around space and longer halting \& parking space.

Depots: Depots with larger areas are used for parking, maintenance facilities and workshop. Since the BRTS buses are of $12.00 \mathrm{~m}$ and $18.00 \mathrm{~m}$ length for normal and articulated buses respectively, new depots with special maintenance and repair facilities are constructed. Usually they are dedicated for the BRTS buses alone and other buses do not use these facilities.

Auto vehicle washing system is provided. Photo 3 shows the automatic vehicle washing system.

Feeder Services: Any isolated BRT system does not prove to be effective in bringing about a paradigm shift in the travel pattern of any city. It has to be supported and endorsed by all other means of mobility so as to have a more comprehensive impact on the city transport system. Footpaths for pedestrians, feeder services using smaller buses or Para-transit, parking management etc., also contribute to the BRTS.

So feeder services are provided with other normal buses which can bring commuters from interior places to the BRTS corridor.

Parking: Provision for parking areas for private vehicles is provided so as to promote Park and Ride as an integral part of a well-designed BRT system. Parking areas are especially required in and around the terminals and major bus stops. There needs to be easy and smooth access to the BRTS station from the parking areas, if possible with integrated BRTS tickets and parking charges.

\section{IMPLEMENTATION OF SOFTWARES IN HDBRTS:

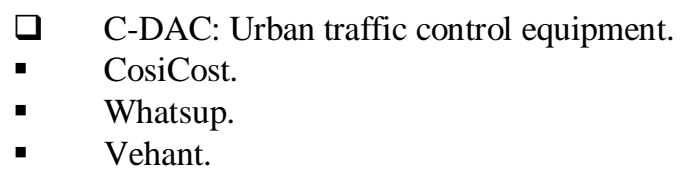

C-DAC: It controls all the camera systems located at BRTS terminals, bus stops, \& BRTS buses.

Cosi Cost : Sensor based auto bollards auto control device developed by K.L.E.Technological University Hubballi. Yet to be provided.

Whatsup : To indicate the live position of flap doors and displays through network diagram.

Vehant: To capture number plates of vehicles.

BRTS bus stops provided with modern features and safety precautions. Entrance is provided with S.S handrails and tactile flooring to guide movement for blind people. Inside the bus stops LED lightings are provided. Cameras are provided inside the station, inside the buses and outside the bus stops. Safety precautions \& features provided inside the BRTS bus like fire extinguishers and holding belts. Wheel chairs' locking system is provided inside the bus for physically disabled persons. Emergency exit is provided for buses.

\section{MERITS OF HDBRTS:}

- $\quad$ The HDBRTS has segregated lanes which are meant for BRTS buses only.

- Rigid pavement is provided throughout the corridor which helps in preventing deterioration due to fatigue and rutting failure of the pavement especially at wheel locations at bus stops.

- The HDBRTS is provided with off-board ticket collection system which avoids delay in running BRTS buses. 
- The HDBRTS buses are provided with safety measures such as, seat belts, emergency exists, stop buttons, etc..

- The capacity of BRTS lanes are sufficient for safe overtaking of nonstop buses except at few bus stations.

- The median of BRTS lanes is provided with arboriculture which helps to prevent soil erosion and provides clear distinct vision to the drivers.

- All buses of HDBRTS are provided with airconditioning, and compared to normal buses HDBRTS buses produces only $70 \mathrm{db}$ of sound.

\section{SHORTFALLS OF HDBRTS:}

- The bus stations of HDBRTS are not covered and therefore rain, sun heat, dust may ply into the bus stations that may damage displays.

- The buses of HDBRTS and bus stations are not provided with fire extinguisher and first-aid kit.

- In some of the bus stations boarding and alighting gates have minor problem in operation which needs solution.

- Service roads on both sides not provided and the buildings are dismantled at R.O.W all along the corridor. Mixed traffic is using one lane for parking as no specific parking place is not provided. This is creating problem in overtaking vehicles at normal bus stations and junctions.

\section{ROAD USER SURVEY CONDUCTED IN HDBRTS:}

- This is conducted based on some defined questions and for which answers are taken from road users. The results are as below:

- 1 . How often you travel by BRTS?

- Daily-52\%

- Thrice a week $-21 \%$

- Twice a week $-15 \%$

- Now and then - $12 \%$

- 2.Travelling by BRTS saves time?

- Sufficient time-54\%

- A little time - $27 \%$

- Better compared to usual traffic - $18 \%$

- Not at all $-1 \%$

- 3.Whether BRTS is travelling safe?

- Yes $-92 \%$

- $\mathrm{No}-8 \%$

- 4. Weather BRTS service is useful in case of urgency?

- Yes $-73 \%$

- No-4\%

- Can't say $-23 \%$

- 5 . Weather the BRTS buses run in scheduled time?
- $\quad$ Yes- $82 \%$

- $\mathrm{No}-8 \%$

- Some time no- $6 \%$

- Can't say $-4 \%$

- 6.Are you satisfied with comfort of BRTS buses?

- Much satisfied - 66\%

- $\quad$ Some what satisfied $-33 \%$.

- Not at all satisfied - $1 \%$

- 7.Is it easier to reach to the BRTS bus stop for boarding the bus?

- Yes $-83 \%$

- No- $17 \%$

- 8.Whether BRTS level boarding and alighting is comfortable?

- Very comfortable $-37 \%$

- Comfortable -58\%

- Uncomfortable-4\%

- Very uncomfortable - $1 \%$

- 9.How do you rate the BRTS service? (Maxi 4 stars)

- Four stars $-2 \%$

- Three stars $-78 \%$

- Two stars $-0 \%$

- One star $-20 \%$

- 10.Which of the following factors about BRTS attract you the most?

- A.C.Volvo bus $-35 \%$

- Time factor $-52 \%$

- Segregated bus lane $-2 \%$

- Levelling boarding and alighting $-1 \%$

- 11.Before BRTS in which way you would travel?

- By two wheelers $-21 \%$

- By three wheelers $-7 \%$

- By four wheelers - 7\%

- By govt. buses (public transport) - $65 \%$

Table-2: COMPARISION OF PUNE BRTS AND HDBRTS:

\begin{tabular}{|l|l|}
\hline \multicolumn{1}{|c|}{ HDBRTS } & \multicolumn{1}{c|}{ PUNE BRTS } \\
\hline $\begin{array}{l}\text { Provided with off-board fare } \\
\text { collection system. }\end{array}$ & $\begin{array}{l}\text { Provided with on-board fare } \\
\text { collection system. }\end{array}$ \\
\hline $\begin{array}{l}\text { Bus stations are not covered and } \\
\text { therefore dust, sun heat, rain will } \\
\text { affect the public and electronic } \\
\text { equipments inside the bus stations. }\end{array}$ & $\begin{array}{l}\text { Bus stations are covered, which } \\
\text { provides protection from dust, sun } \\
\text { heat thefts, etc. }\end{array}$ \\
\hline $\begin{array}{l}\text { Provided with segregated lanes. } \\
\text { Mrovided with arboriculture which } \\
\text { prevents soil erosion in medians.. }\end{array}$ & $\begin{array}{l}\text { segregated hence mixed traffic is } \\
\text { entering BRTS lanes making the } \\
\text { traffic congestion. }\end{array}$ \\
\hline
\end{tabular}


XIX. CONCLUSION

Based on the study, the following conclusions are drawn:

1. Service roads must be provided on both sides beyond the MTL especially when the corridors run in city limits.

2. Bus bays and specific parking places should be provided all along the corridors to avoid traffic congestion.

3. Closed bus shelters should be preferred to avoid effect of rain, dust and heat.

4. The roof of the bus shelters can be used with solar panels to have electric power and thus making the shelter self sustainable.

5. Self structured roofs (Truss less roof)) may be adopted with solar panels to achieve economy.

6. Each bus shelter may be provided with bore well water. This water can be used for drinking \& sanitary purpose and to water median plantation.

7. Each bus shelter should be provided with water supply and sanitary unit badly required for working staff.

8. The hand rail for segregation of BRTS and MTL should be constructed with concrete blocks for a height of 900MM and then S.S railing may be provided for aesthetic and ease of maintenance. The M.S and Chain link barricades should be avoided as they require much maintenance.

9. Signal synchronisation should be done as per actual ground condition for peak and non peak hours.

10. Corridors must be extended for all the important interior routes to make the BTRS system a success.

\section{ACKNOWLEDGEMENT}

1. Pune BRTS authorities: Hon. Chairman and Managing Director, Pune Mahanagar Parivahan Mahamandal Ltd.

2. Hubballi Dharwad BRTS authorities: Managing Director.

\section{REFERENCE}

[1] Hon. Chairman and Managing Director Pune Mahanagar Parivahan Mahamandal Ltd. http://www.pmpml.org

[2] Commissioner, Directorate of Urban land Transport Government of Karnataka and Managing Director HDBRTS (2012-2018) . Wikipedia . Web: http://www.hdbrts.co.in 